\title{
Expanding the Epigenetic Landscape: Novel Modifications of Cytosine in Genomic DNA
}

\author{
Skirmantas Kriaucionis ${ }^{1}$ and Mamta Tahiliani ${ }^{2}$ \\ ${ }^{1}$ Ludwig Institute for Cancer Research Ltd., University of Oxford, Nuffield Department of Clinical Medicine, Old Road Campus \\ Research Building, Headington, Oxford OX3 7DQ, United Kingdom; ${ }^{2}$ Skirball Institute/NYU School of Medicine, New York, \\ New York 10016 \\ Correspondence: mamta.tahiliani@med.nyu.edu
}

\begin{abstract}
Methylation of the base cytosine in DNA is critical for silencing endogenous retroviruses, regulating gene expression, and establishing cellular identity, and has long been regarded as an indelible epigenetic mark. The recent discovery that the ten eleven translocation (TET) proteins can oxidize 5-methylcytosine $(5 \mathrm{mC})$ resulting in the formation of 5 -hydroxymethylcytosine $(5 \mathrm{hmC})$ and other oxidized cytosine variants in the genome has triggered a paradigm shift in our understanding of how dynamic changes in DNA methylation regulate transcription and cellular differentiation, thus influencing normal development and disease.
\end{abstract}

Methylation of the base cytosine (termed 5-methylcytosine or $5 \mathrm{mC}$ ) is an epigenetic mark often referred to as the fifth base, to underscore its heritability and importance in development. $5 \mathrm{mC}$ is considered an epigenetic mark because it directs biological function (i.e., transcriptional repression) without altering the protein coding capacity of the local DNA sequence dictated by the four conventional bases. $5 \mathrm{mC}$ is vital for processes including embryogenesis, parental imprinting, $\mathrm{X}$ inactivation, the silencing of endogenous retroviruses, and the regulation of gene expression and splicing. Cytosine methylation influences these processes by both modulating protein-DNA interactions and nucleating the formation of repressive heterochromatic structures. In 2009, 5-hydroxymethylcytosine (5hmC) was simultaneously identified by two research groups as a normal constituent of genomic DNA in mammalian neurons and embryonic stem (ES) cells (Kriaucionis and
Heintz 2009; Tahiliani et al. 2009). This landmark finding has stimulated a tremendous amount of research focused on understanding how this modification exerts its influence on the regulation of the genome and how this modification ties into a $5 \mathrm{mC}$ demethylation pathway that was previously lacking in enzymatic players.

$5 \mathrm{hmC}$ was serendipitously identified in Nathaniel Heintz's laboratory when Skirmantas Kriaucionis was elucidating the chromatin make-up of the strikingly euchromatic nuclei of cerebellar Purkinje neurons. Isolating Purkinje cell nuclei in itself was a technical achievement, requiring the use of transgenic mice with an eGFP labeled nucleolus (bacTRAP) and high-capacity fluorescenceactivated cell sorting to get enough material for the assays. The goal was to compare $5 \mathrm{mC}$ abundance in Purkinje cells with granule cells using the classic "nearest neighbor" DNA composition analysis technique dating back to Kornberg's classic experiments of 1961 and used in Adrian Bird's pioneering experiments quantifying global levels of methylated CpGs. Unexpectedly, this sensitive, unbiased, and robust method revealed an additional signal, which was reproducibly enriched in Purkinje neurons and detectable in other neuronal cell types. The most exciting phase of these experiments was identifying the signal as $5 \mathrm{hmC}$, a novel base modification in genomic DNA (Kriaucionis and Heintz 2009).

$5 \mathrm{hmC}$ was concurrently discovered by Mamta Tahiliani in Anjana Rao's laboratory when her quest to identify a

Editors: C. David Allis, Marie-Laure Caparros, Thomas Jenuwein, and Danny Reinberg

Additional Perspectives on Epigenetics available at www.cshperspectives.org

Copyright (C 2014 Cold Spring Harbor Laboratory Press; all rights reserved; doi: 10.1101/cshperspect.a018630

Cite as Cold Spring Harb Perspect Biol 2014;6:a018630 
DNA demethylase took an unexpected twist. The search for such an enzyme was primarily motivated by the demonstration that DNA methylation is actively erased in the paternal genome immediately after fertilization. This seminal finding strongly suggested that resetting methylation patterns might be critical for epigenetic reprogramming (as illustrated in Fig. 3 of Li and Zhang 2014). Mamta's bioinformatics collaborator L. Aravind predicted that the TET family of proteins were dioxygenases with a specificity for nucleic acids. Distantly related dioxygenases had recently been shown to remove methyl groups from both histones and damaged DNA bases. Therefore, the TET proteins were extremely attractive DNA demethylase candidates. In her initial experiments, Mamta found that overexpression of TET1 diminished levels of $5 \mathrm{mC}$ by immunofluorescence, suggesting tantalizingly that TET1 was acting as a true DNA demethylase. However, her attempts to confirm demethylation using thin-layer chromatography yielded puzzling results because the reduction in $5 \mathrm{mC}$ was not accompanied by the predicted increase in cytosine. However, when she adjusted the contrast on the scanned image, she noticed that what had appeared to be a faint smear under cytosine took on the shape of an independent spot suggesting that TET1 might be converting $5 \mathrm{mC}$ to a novel species. Because many dioxygenases initiate catalysis by hydroxylating their substrates, Mamta hypothesized and then confirmed that this nucleotide was $5 \mathrm{hmC}$. The group also showed that $5 \mathrm{hmC}$ was present in the genome of ES cells, and that both TET1 and 5hmC levels decline when ES cells are differentiated. This suggested that $5 \mathrm{hmC}$ is a normal constituent of mammalian DNA, and that TET proteins and $5 \mathrm{hmC}$ play an important role in regulating gene expression and cell identity in ES cells (Tahiliani et al. 2009). Subsequent studies by multiple laboratories have established that each member of the TET family (TET1/TET2/TET3) is able to convert $5 \mathrm{mC}$ to $5 \mathrm{hmC}$ (Wu and Zhang 2011). However, studies in mice have shown that Tet 3 is the only member of the TET family required in vivo for normal development.

The discovery that TET enzymes can oxidize $5 \mathrm{mC}$ to $5 \mathrm{hmC}$ led to the question of whether full DNA demethylation from $5 \mathrm{hmC}$ to $\mathrm{C}$ was passive (i.e., achieved by replication-dependent dilution), or actively catalyzed. TET enzymes have now been shown to successively oxidize $5 \mathrm{hmC}$ to 5-formylcytosine (5fC) and 5-carboxylcytosine (5acC); reviewed in $\mathrm{Wu}$ and $\mathrm{Zhang} 2011$ ). The rapid loss of $5 \mathrm{mC}$ in the paternal genome coincides with the translocation of TET3 to the nucleus and the large-scale conversion of $5 \mathrm{mC}$ to $5 \mathrm{hmC}, 5 \mathrm{fC}$, and $5 \mathrm{caC}$ (Wu and Zhang 2011). Immunostaining of metaphase chromatin further revealed that all three oxidized derivatives of $5 \mathrm{mC}$ are largely retained on the original strands of DNA and are passively diluted by replication during the early cleavage cycles, indicating that TET-mediated oxidation of $5 \mathrm{mC}$ can stimulate passive loss of $5 \mathrm{mC}$ oxidation products through replication. Alternatively or even concurrently, $5 \mathrm{fC}$ and $5 \mathrm{caC}$ can be removed by thymine DNA glycosylate (TDG) and replaced by cytosine via base excision repair (Fig. 1A) (Wu and Zhang 2011; Fig. 6 of Li and Zhang 2014). When and where in the genome these mechanisms operate remains a topic of active research.

Understanding the biological function of $5 \mathrm{hmC}$ has required the development of innovative tools to detect it and distinguish it unequivocally from $5 \mathrm{mC}$ and $\mathrm{C}$. It is clear now that bisulfite sequencing cannot distinguish $5 \mathrm{hmC}$ from $5 \mathrm{mC}$, and also misinterprets $5 \mathrm{fC}$ and $5 \mathrm{caC}$ as cytosine (Pastor et al. 2013). Therefore, it is important to note that decades of bisulfite sequencing data must be interpreted with caution, as "methylation" could be either $5 \mathrm{mC}$ or $5 \mathrm{hmC}$, whereas positions previously identified as cytosine could actually contain $5 \mathrm{fC}$ or $5 \mathrm{caC}$. A number of techniques have now been developed to enrich for $5 \mathrm{hmC}$-containing DNA and most recently to sequence it at single nucleotide resolution (Pastor et al. 2013).

Multiple lines of evidence indicate that $5 \mathrm{hmC}$ is not simply a demethylation intermediate, but rather a novel modification in DNA with an effector program of its own. $5 \mathrm{hmC}$ is present in a variety of mature cell types in adult organisms, and its levels range from $0.05 \%$ of all bases in some immune cells to as high as $0.6 \%$ in Purkinje cells. This leads to the question of whether readers of this mark exist to translate the presence of this modification into biological function, much as unmethylated cytosines can be read by CXXC domain-containing proteins (see Blackledge et al. 2013), or methylated CpGs are recognized by MBD proteins. A number of proteins have already been identified that bind to $5 \mathrm{hmC}$ including MeCP2, MBD3, and Uhrf2, which are known to regulate transcription. $5 \mathrm{fC}$ - and $5 \mathrm{caC}$ bound proteins include a number of DNA repair proteins, consistent with a role for these modifications as demethylation intermediates.

The cell type, developmental stage, and genomic locus specific distribution of $5 \mathrm{hmC}$ is beginning to suggest particular functions of this DNA modification. Techniques enriching for $5 \mathrm{hmC}$ as well as single nucleotide sequencing techniques have shown that in ES cells $5 \mathrm{hmC}$ levels are elevated at enhancers and $\mathrm{CpG}$ island (CGI)-containing promoters, which are free of methylation despite their high CpG content (Pastor et al. 2013). In neuronal cells, $5 \mathrm{hmC}$ is enriched in gene bodies (Fig. 1B,C) (Mellén et al. 2012; Pastor et al. 2013). Although gene body enrichment was also noted in ES cells, single nucleotide techniques have not verified this finding. It has been proposed that TET proteins and $5 \mathrm{hmC}$ play a role in keeping CGIs free of 
A ES cell-poised
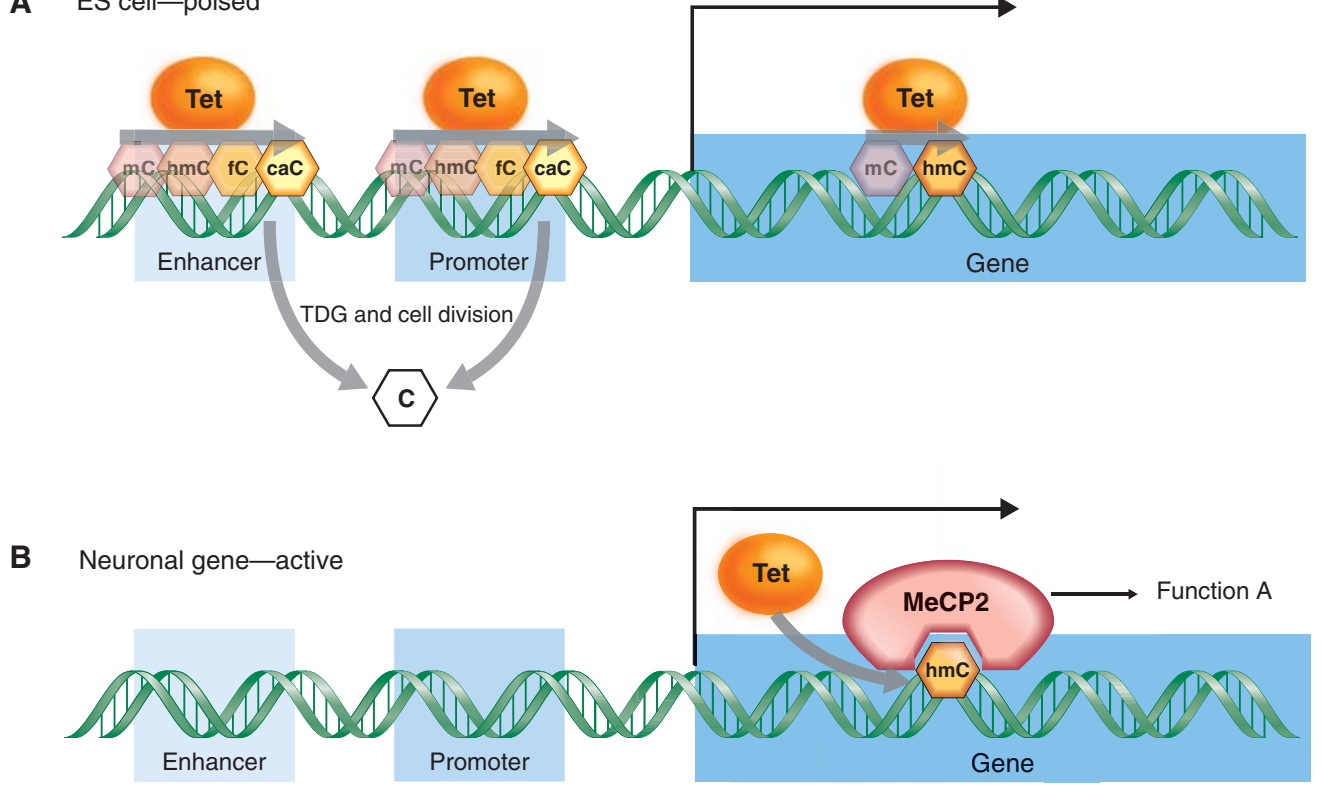

C Neuronal gene-silent
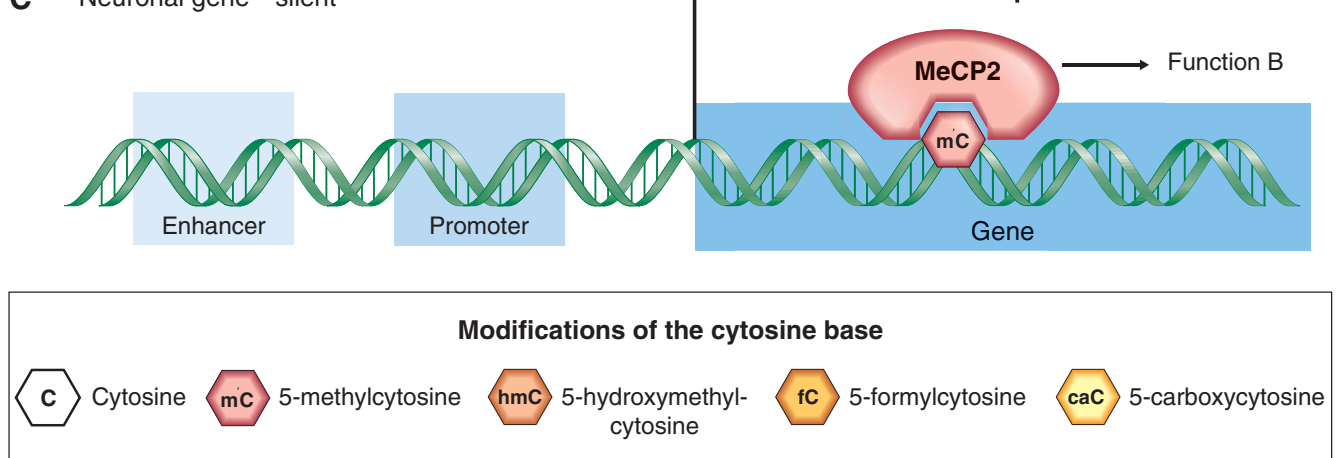

Figure 1. Distribution and metabolism of cytosine modifications within genes in ES cells and neurons. $(A)$ TETmediated oxidation of $5 \mathrm{mC}$ followed by base excision repair (BER)-mediated removal of $5 \mathrm{caC}$ keeps promoters and enhancers free of methylation in ES cells. It is also possible that oxidation of $5 \mathrm{mC}$ blocks maintenance methylation at these regions. MeCP2 binds both $5 \mathrm{mC}(B)$ and $5 \mathrm{hmC}(C)$ in neuronal gene bodies, where the cytosine modification state correlates with the level of expression.

methylation in ES cells, whereas the function of gene body $5 \mathrm{hmC}$ in neuronal cells is still unclear.

Future research will need to address the precise function of $5 \mathrm{hmC}$ in early development, hematopoiesis and neuronal function. It will be intriguing to know whether a single model can explain $5 \mathrm{hmC}$ function in all cell types or whether its function will vary for each cell type examined.

\section{REFERENCES}

* Reference is also in this collection.

* Blackledge NP, Thomson JP, Skene PJ. 2013. CpG island chromatin is shaped by recruitment of ZF-CxxC proteins. Cold Spring Harb Perspect Biol 5: a018648.
Kriaucionis S, Heintz N. 2009. The nuclear DNA base 5-hydroxymethylcytosine is present in Purkinje neurons and the brain. Science 324: 929-930.

* Li E, Zhang Y. 2014. DNA methylation in mammals. Cold Spring Harb Perspect Biol doi: 10.1101/cshperspect.a019133.

Mellén M, Ayata P, Dewell S, Kriaucionis S, Heintz N. 2012. MeCP2 binds to $5 \mathrm{hmC}$ enriched within active genes and accessible chromatin in the nervous system. Cell 151: 1417-1430.

Pastor WA, Aravind L, Rao A. 2013. TETonic shift: Biological roles of TET proteins in DNA demethylation and transcription. Nat Rev Mol Cell Biol 14: 341-356.

Tahiliani M, Koh KP, Shen Y, Pastor WA, Bandukwala H, Brudno Y, Agarwal S, Iyer LM, Liu DR, Aravind L, et al. 2009. Conversion of 5methylcytosine to 5-hydroxymethylcytosine in mammalian DNA by MLL partner TET1. Science 324: 930-935.

Wu H, Zhang Y. 2011. Mechanisms and functions of Tet protein-mediated 5-methylcytosine oxidation. Genes Dev 25: 2436-2452. 


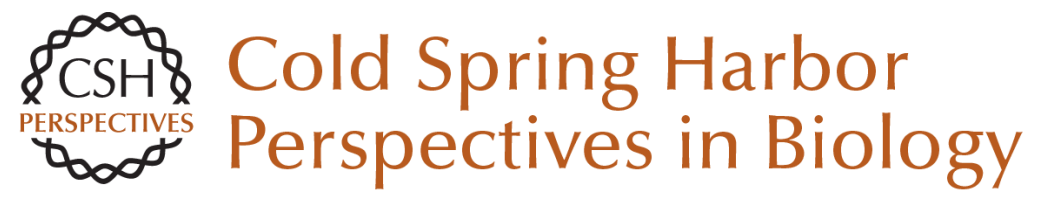

\section{Expanding the Epigenetic Landscape: Novel Modifications of Cytosine in Genomic DNA}

Skirmantas Kriaucionis and Mamta Tahiliani

Cold Spring Harb Perspect Biol 2014; doi: 10.1101/cshperspect.a018630

\section{Subject Collection Epigenetics}

Metabolic Signaling to Chromatin

Shelley L. Berger and Paolo Sassone-Corsi

Histone and DNA Modifications as Regulators of

Neuronal Development and Function Stavros Lomvardas and Tom Maniatis

Histone Modifications and Cancer James E. Audia and Robert M. Campbell

Epigenetics and Human Disease Huda Y. Zoghbi and Arthur L. Beaudet

Induced Pluripotency and Epigenetic Reprogramming

Konrad Hochedlinger and Rudolf Jaenisch

Long-Range Chromatin Interactions Job Dekker and Tom Misteli

RNAi and Heterochromatin Assembly Robert Martienssen and Danesh Moazed

Dosage Compensation in Drosophila John C. Lucchesi and Mitzi I. Kuroda
Epigenetic Determinants of Cancer Stephen B. Baylin and Peter A. Jones

Maintenance of Epigenetic Information Geneviève Almouzni and Howard Cedar

A Structural Perspective on Readout of Epigenetic Histone and DNA Methylation Marks Dinshaw J. Patel

The Necessity of Chromatin: A View in

Perspective Vincenzo Pirrotta

Germline and Pluripotent Stem Cells Wolf Reik and M. Azim Surani

Comprehensive Catalog of Currently Documented Histone Modifications Yingming Zhao and Benjamin A. Garcia

Epigenetic Regulation of Chromatin States in Schizosaccharomyces pombe Robin C. Allshire and Karl Ekwall

Histone Variants and Epigenetics Steven Henikoff and M. Mitchell Smith

For additional articles in this collection, see http://cshperspectives.cshlp.org/cgi/collection/

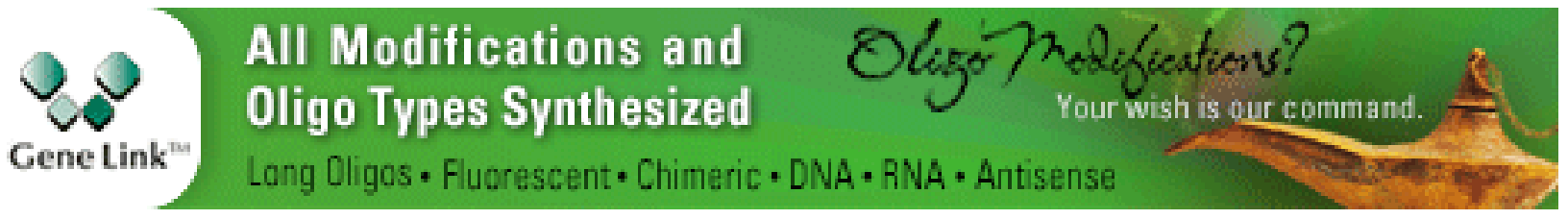

Copyright (C 2014 Cold Spring Harbor Laboratory Press; all rights reserved 
For additional articles in this collection, see http://cshperspectives.cshlp.org/cgi/collection/

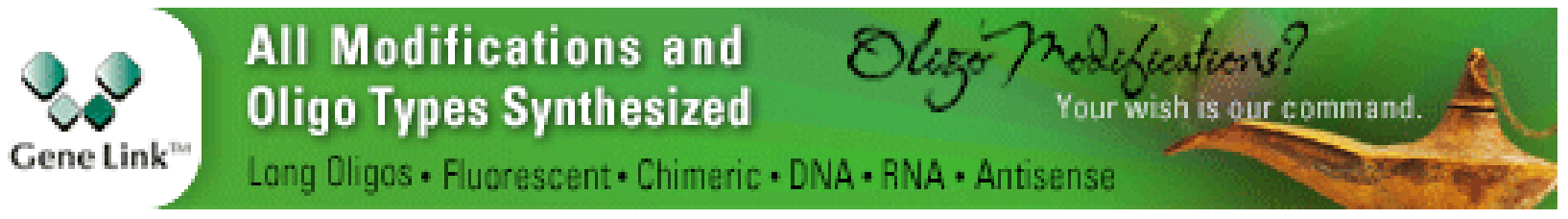

Copyright @ 2014 Cold Spring Harbor Laboratory Press; all rights reserved 